\title{
Thai Art Pattern Design from Folk Wisdom's Banana Stalk Carving Using the Geometer's Sketchpad (GSP)
}

\author{
N. W. Sangwaranatee, N. Sangwaranatee, and K. Suraprap
}

\begin{abstract}
This paper presents the design of classical Thai art pattern using GSP for folk wisdom banana stalk carving. The application of computer program is applied in Thai art pattern design using the properties and principles of mathematics and mathematical equations. GSP can help the creation of Thai art pattern design for folk wisdom banana stalk carving with more effective, less time consuming, more convenient, and more accuracy. It requires very high skill to design the pattern manually because it tends to distort easily. The art of banana stalk carving has been a valuable Thai handicraft for generations which needs to be preserved for the country's pride.
\end{abstract}

Index Terms-The Geometer's Sketchpad, folk wisdom's banana stalk carving, Thai art pattern.

\section{INTRODUCTION}

Geometer's Sketchpad (GSP) is an effective computer program which is capable in several fields of mathematic [1]; the researcher realizes the significance of this program together with the mathematical equations and principles of mathematics in Thai art pattern design. This can help in more convenience, more pattern accuracy, and less time consuming especially in Thai art pattern design for folk wisdom banana stalk carving. The design of Thai art pattern has been the local wisdom which is the country identity for a long time. The skills have been transferred from generations through particular individual high skilled artists. The researcher noticed that the application of GSP in graph plotting [2]-[3] can create delicate and clear patterns and can be recorded. Moreover, the pattern can be decorated for more complicated and delicate details. For traditional Thai art pattern design, it requires very high skill to design the pattern manually because it tends to distort easily. In addition, the same pattern can be different due to particular individual artists. The researcher applied Geometer's Sketchpad (GSP) in Thai art pattern design integrated with local wisdom of banana stalk carving in Pethchaburi Province to preserve the valuable local wisdom for the country's pride. It is hoped that this study can be effectively applied to preserve and disseminate the art of banana stalk carving as one of the valuable Thai handicraft.

Manuscript received May 15, 2014; revised July 13, 2014. This work was supported in part by Suan Sunandha Rajabhat University, Bangkok, Thailand.

The authors are with Suan Sunandha Rajabhat University, Bangkok, Thailand (e-mail: Nisakorn.su@ssru.ac.th).

\section{RELATED WORKS}

\section{A. The Geometer's Sketchpad (GSP)}

GSP program is an effective IT application that helps learners create new knowledge by applying with mathematics. The use of GSP program is integrated with the mathematics and information technology leading to the development of multiple intelligences including language knowledge, logics, dimension relations, and arts [4].

The design of Thai art pattern through GSP requires the graph plotting functions and principles of mathematics, reflection, translation, and vector and locus construction. Fig. 1 below presents graph plotting function.

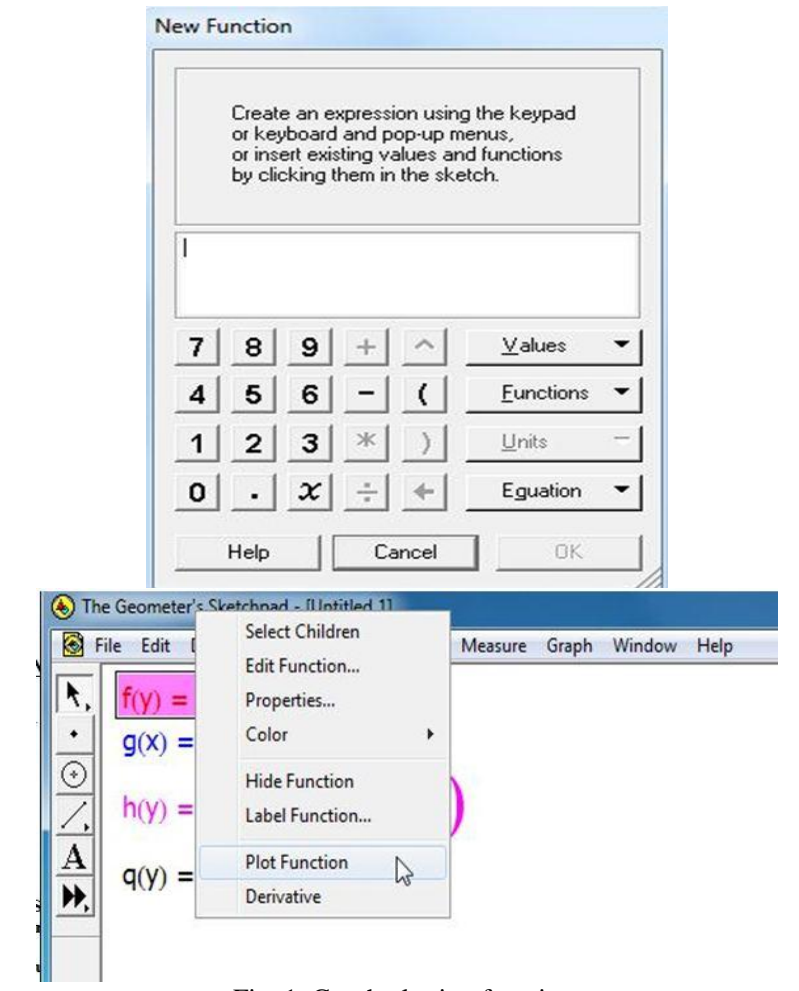

Fig. 1. Graph plotting function.

\section{B. The Art of Banana Stalk Carving}

The art of banana stalk carving at Pethchaburi Province [5] has been the local wisdom since Ayutthaya period and came to Pethchaburi around the end of Ayutthaya range and has been developed for generations of both patterns and method becoming the folk art of the province by mixing with the local tradition art of Pethchaburi.

Pethchaburi Province has been very famous for traditional handicraft with various schools of arts. The artists have transferred their skills among their groups as can be seen in the artworks in several temples such as Wat Yai Suwannaram 
School, Chang Wat Koh School, Wat Prasong School, and Wat Yang School, etc. Fig. 2 shows the artist is carving banana stalk and Fig. 3 shows Tools for banana stalk carving. Pethchaburi banana stalk carving is the special art for the decoration of crematory (Meru Mountain) which is different from other cremation cultures as presented in Fig. 4. It requires time for designing the Thai art pattern and constructing the crematory which is very special Pethchaburi Handicraft School. The mortuary urn used to contain the body instead of the coffin is supported by crematory with beautiful decoration of banana stalk carving similar to royal cremation. In general, normal folks should not manage this type of cremation. However, it has been the traditional folk cremation in Pethchaburi Province but only a few now because of very high expense.

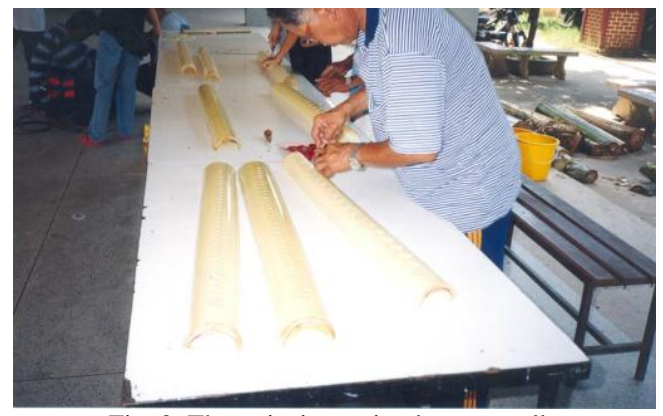

Fig. 2. The artist is carving banana stalk.

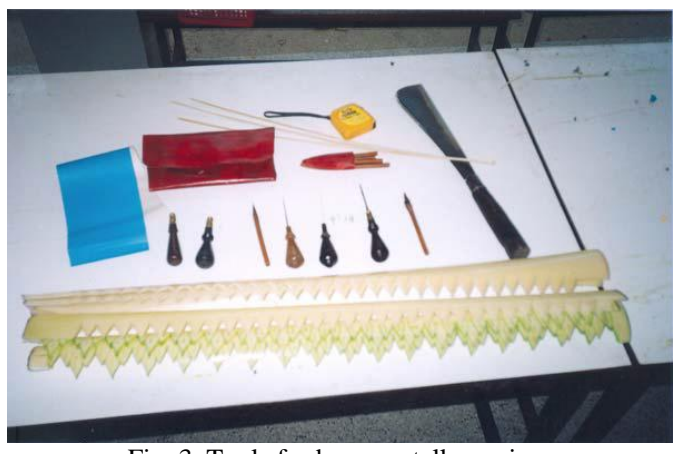

Fig. 3. Tools for banana stalk carving.

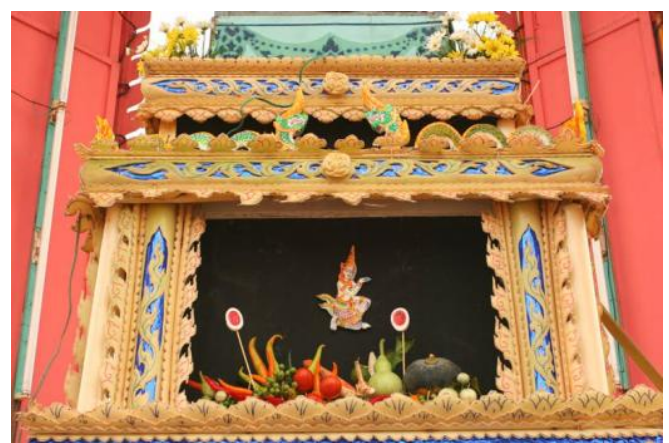

Fig. 4. Banana stalk carving decoration at the crematory.

\section{The DESIGN OF TA-OY PATtERn FOR THE BANANA STALK CARVING USING GSP}

Starting from plotting a graph of the following equations using GSP

$$
\begin{gathered}
f(y)=-\sin \sqrt{7 y} \\
g(x)=x^{2}+2
\end{gathered}
$$

$$
\begin{gathered}
h(y)=-\left(\left(\frac{1}{2} y-1\right)^{2}-2\right) \\
q(y)=\sin \sqrt{6 y}
\end{gathered}
$$

Select menu, graph $\rightarrow$ new function; there will be a window to create function. Put the 4 equations above in the response box for creating new function; then create the graph of the functions by clicking at the right of the mouse $\rightarrow$ draw function graph.

Define function range $f(y)$ when $y \in[3,5.6]$ and define function range $g(x)$ when $x \in[0.99,1.3]$ and $h(y)$ when $y \in[0,3.67]$ and $q(y)$ when $y \in[0,1.65]$ and define the example to be discontinuous type to get the graph without arrow head, right click on the mouse $\rightarrow$ property. When completing the graphs of 4 functions, the Ta-Oy Pattern will be shown in the quadrant 1 as shown in Fig. 5 .

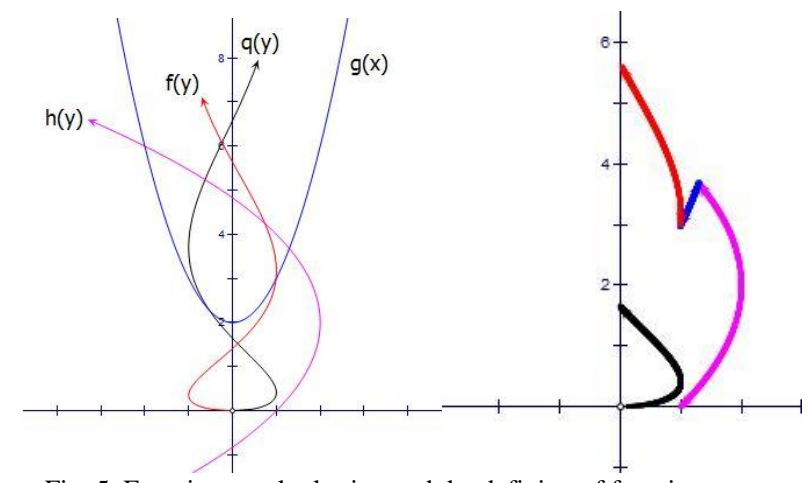

Fig. 5. Function graph plotting and the defining of function range

Function $f(y)$ will be plotted on $[3,5.6]$ by plotting $(0,3)$ and $(0,5.6)$ choosing graph menu $\rightarrow$ then, plotting $(0,3)$ and $(0,5.6)$; after that, create a straight line by clicking at the 2 points $\rightarrow$ construction menu $\rightarrow$ straight-line part ; then create a point on the straight-line part by choosing straight-line part $\rightarrow$ graph menu $\rightarrow$ point on the straight-line part; then, hide it to prevent from getting confused and repeat the steps at every function. After that, measure the range of each point for plotting on the graph as illustrated in Fig. 6.

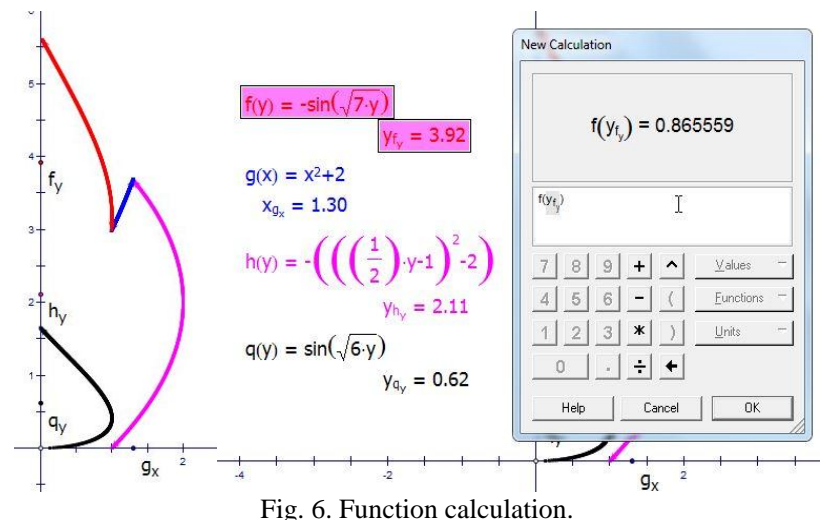

After having the required points, start the reflection by choosing the line needed to be reflection. Here, the reflection will be on $y$ axis; by choosing $y$ axis $\rightarrow$ Transform 
menu $\rightarrow$ identifying the reflection line and it will blink as demonstrated in Fig. 7. Do this for the 4 functions.

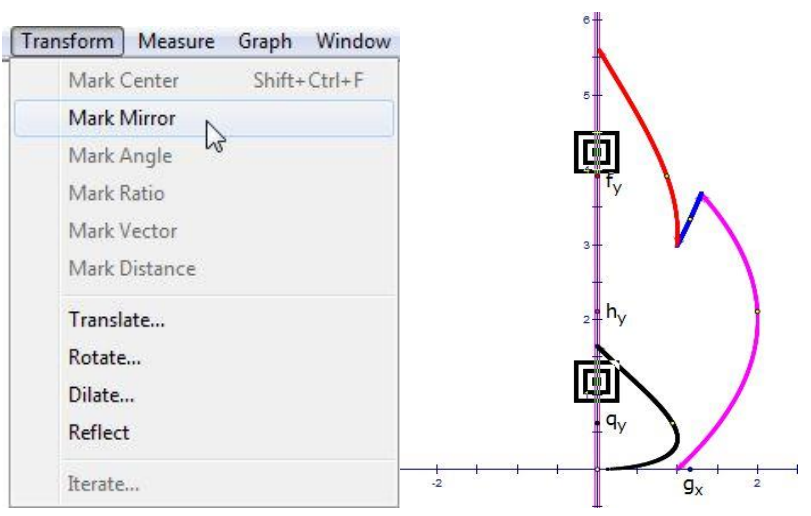

Fig. 7. Reflection.

When getting the reflection points, create locus by choosing at the reflection point of each function on the axis. For example, locus of function $f(y)$, choose function reflection $\rightarrow$ points $\rightarrow$ Construct menu $\rightarrow$ locus. Locus construction shows in Fig. 8 below.

\section{UNITS}

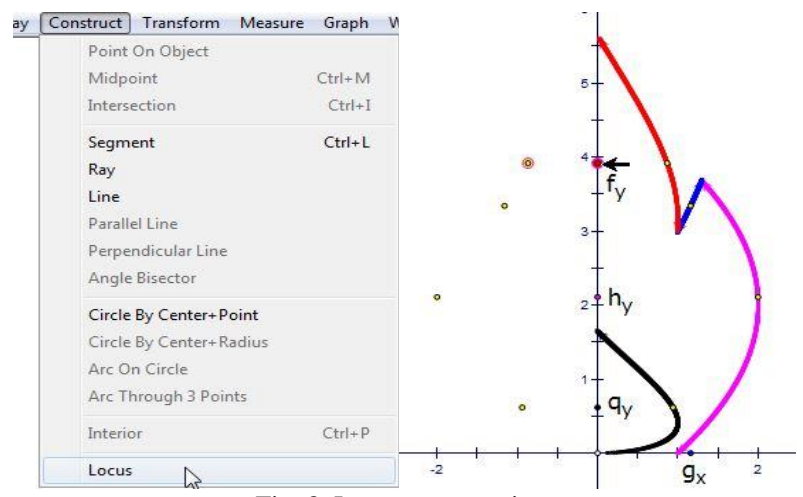

Fig. 8. Locus construction.

Do this at the 4 points and you will get Ta-Oy Pattern as required as presented in Fig. 9.

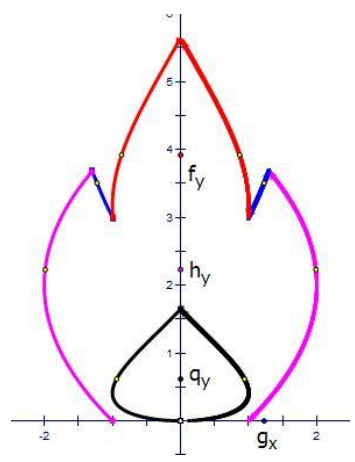

Fig. 9. Ta-Oy pattern.

When getting the prototype, Ta-Oy Pattern can be added on both left and right of the prototype with the pattern boundary at $[-2,2]$ then, plot $(-2,0)$ and $(2,0)$ to define the boundary of the pattern for defining vector on translation. After getting the 2 points, do the translation to the right at $(-2,0)$ and $(2,0)$ respectively. After that, plot on the vector for the translation of the prototype to the required direction by choosing the 2 points $\rightarrow$ transform menu $\rightarrow$ define vector. It can be noticed that there is a dotted line from $(-2,0)$ to $(2,0)$. After defining the vector, the translation will be plotted on the prototype by choosing the points $\rightarrow$ transform menu $\rightarrow$ translation, response box for translation will appear. You will see points for translation for your decision. After choosing the required points, create locus by choosing the required points of each function. For example, function $f$, choose translation points $\rightarrow$ function $f$ point. Do this at every translation function and you will get the new Ta-Oy Pattern as illustrated in Fig. 10.

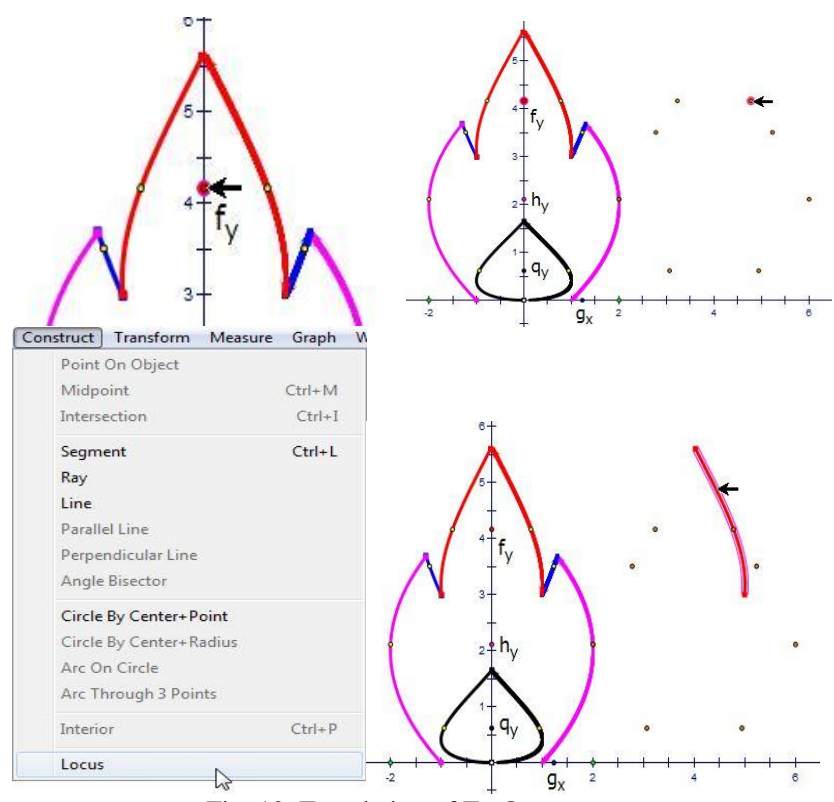

Fig. 10. Translation of Ta-Oy pattern.

Translation can create several Ta-Oy Patterns for the banana stalk carving as presented in Fig. 11.

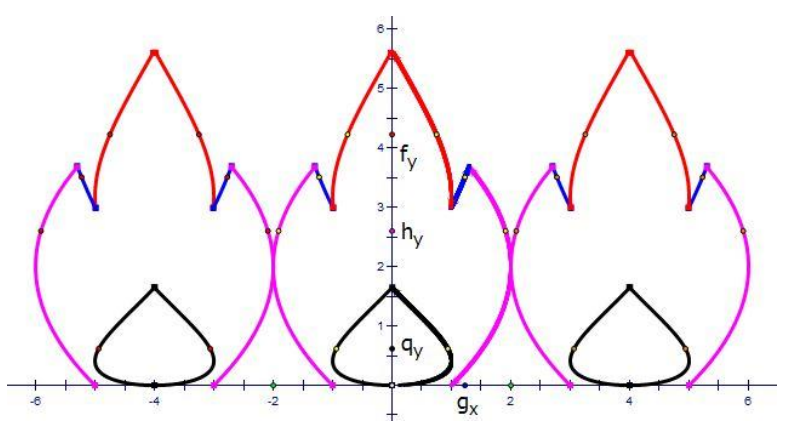

Fig. 11. Ta-Oy pattern after the translation.

\section{RESUlts}

We can create other Thai art patterns for banana stalk carving using GSP as follows.

1) Fun Nueng Pattern

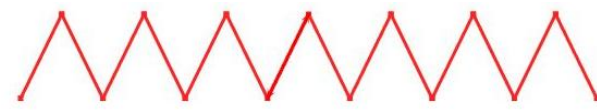

Fig. 12. Fun Nueng Pattern for banana stalk carving.

\section{2) Ta-Oy Pattern}




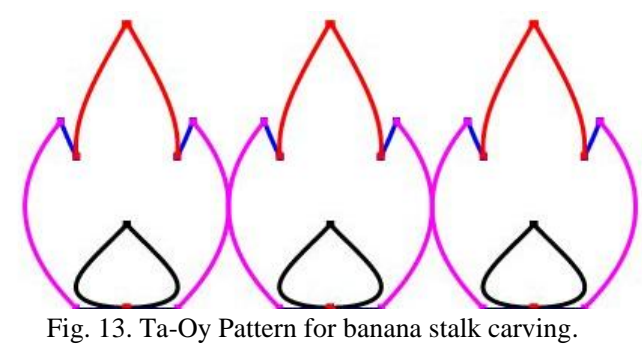

3) Fun Ha Pattern

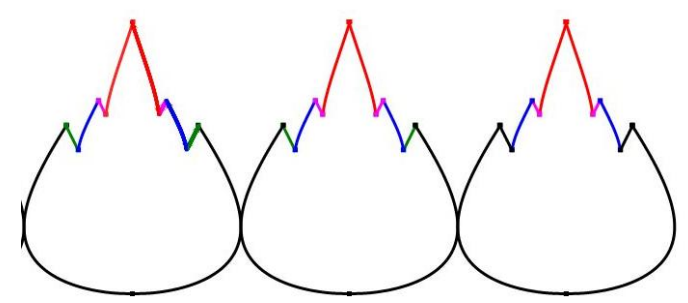

Fig. 14. Fun Ha Pattern for banana stalk carving.

Fun Nueng Pattern, Ta-Oy Pattern and Fun Ha Pattern are demonstrated in Fig 12-14 respectively. The Thai art patterns can be printed out in paper as the required numbers and place on the banana stalks for carving. The carving will be in the same standard with accurately required decorations.

\section{CONCLUSION}

The application of GSP in Thai art pattern design together with the properties and principles of mathematics such as reflection, locus creation, and function plotting can help the creation of Thai art pattern design for folk wisdom banana stalk carving with more effective, less time consuming, more convenient, and more accuracy. It requires very high skill to design the pattern manually because it tends to distort easily from the original. The GSP program helps reduce this kind of error enormously. The art of banana stalk carving has been a valuable Thai handicraft for generations which needs to be preserved for the country's pride.

\section{ACKNOWLEDGMENT}

The authors would like to thank Research and Development Institute of Suan Sunandha Rajabhat University, Thailand for providing a financial fund for this research.

\section{REFERENCES}

[1] L. L. Margaret, "The effects of the geometer's sketchpad software on achievement of geometric knowledge of high school geometry students," Dissertation Abstracts International, vol. 57, no. 6, pp. 2611-A, 1996

[2] F. Almeqdadi, 'The effect of using the geometer's sketchpad (GSP) on Jordanian students' understanding of geometrical concepts," in Proc. the International Conference on Technology in Mathematics Education; 2000, p. 171.

[3] Key Curriculum press, Teaching Geometry with the Geometer's Sketchpad. Berkeley, California: key curriculum press, 2001.

[4] N. W. Sangwaranatee, C. Noradee, K. Suraprap, and K. Bussaban, "Designing cartoon characters for string art Using the GSP," in Proc.the International Science, Social Science, Engineering and Energy Conference; 2013.

[5] Libmedia [Online]. www.snc.lib.su.ac.th/libmedia/e-book/yuak.pdf.

Available:

N. W. Sangwaranatee was born in 1981, at Nakronratchasima province, Thailand. She received bachelor, master degrees and $\mathrm{PhD}$ degree in applied mathematics from King Mongkut's Institute of Technology Ladkrabang, Bangkok, Thailand. Currently, she is working as a lecturer at the Department of Informatics Mathematics, Faculty of Science and Technology, Suan Sunandha Rajabhat University, Bangkok, Thailand. Her research is focused on mathematical modeling operations research and educational technology.

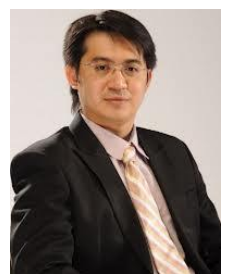

N. Sangwaranatee was born in 1981, at Phetchaboon province, Thailand. He received bachelor's degree in physics from Thepsatri Rajabhat University, Lopburi, Thailand. He obtained master's and $\mathrm{PhD}$ degrees in applied physics from King Mongkut's Institute of Technology Ladkrabang, Bangkok, Thailand. Currently, he is working as a lecturer at the Department of Applied Physics, Faculty of Science and Technology, Suan Sunandha Rajabhat University, Bangkok, Thailand. His research is focused on optics and educational technology.

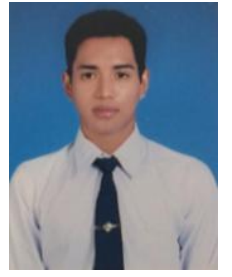

K. Suraprap was born in 1991, at Rayong province, Thailand. Now, he is studying at the Department of Informatics Mathematics, Faculty of Science and Technology, Suan Sunandha Rajabhat University, Bangkok, Thailand. His research is focused on educational technology. 